\title{
Antidepressant-Like Effects of Dracocephalum moldavica L. in Mouse Models of Immobility Tests
}

\author{
Marcos Ignacio Jiménez Zúñiga ${ }^{1}$, Alejandro Jonathan Hurtado Mariles ${ }^{1}$, José Luis Castrejón Flores ${ }^{2}$, José \\ Antonio Mondragón Herrera ${ }^{1,3}$, María Guadalupe Ramírez Sotelo', Genaro Iván Cerón Montes ${ }^{4}$, Yolanda de \\ las Mercedes Gómez y Gómez ${ }^{1, *}$
}

Marcos Ignacio Jiménez Zúñiga', Alejandro Jonathan

Hurtado Mariles ${ }^{1}$, José

Luis Castrejón Flores²,

José Antonio Mondragón

Herrera ${ }^{1,3}$, María Guadalupe

Ramírez Sotelo ${ }^{1}$, Genaro Iván

Cerón Montes ${ }^{4}$, Yolanda de las

Mercedes Gómez y Gómez ${ }^{1, *}$

'Laboratorio de Farmacología, Instituto

Politécnico Nacional, Unidad Profesional

Interdisciplinaria de Biotecnología, MEXICO.

¿ Laboratorio de Biotecnología Moleculary

Cultivo Celular, Av. Acueducto, La Laguna

Ticomán, C.P.: 07340, Gustavo A. Madero,

Ciudad de México, MEXICO.

${ }^{3}$ Centro Médico Nacional Siglo XXI,

Hospital de Cardiología, Laboratorio

de Patología Molecular, Avenida

Cuauhtémoc 330, Doctores, C.P.

06720, Cuauhtémoc, Ciudad de

MEXICO.

${ }^{4}$ Universidad Tecnológica de Tecámac,

Laboratorio de Bioprocesos, Carretera

Federal México-Pachuca, Km. 37.5, Predio

Sierra Hermosa, C.P. 55740. Tecámac,

Estado de México, MEXICO.

\section{Correspondence}

Yolanda de las Mercedes Gómez y Gómez

Laboratorio de Farmacología, Instituto Politécnico Nacional, Unidad Profesional Interdisciplinaria de Biotecnología,

MEXICO.

\section{E-mail: ygomez@ipn.mx}

History

- Submission Date: 18-05-2019;

- Review completed: 10-05-2019;

- Accepted Date: 10-05-2019.

DOI : 10.5530/pj.2019.11.154

Article Available online

http://www.phcogj.com/v11/i5

\section{Copyright}

(C) 2019 Phcogj.Com. This is an openaccess article distributed under the terms of the Creative Commons Attribution 4.0 International license.

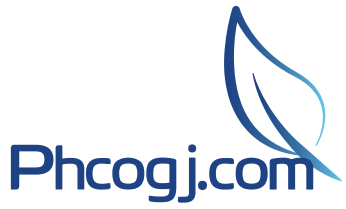

\section{ABSTRACT}

The aim of this investigation was to evaluate the antidepressant activity of the ethanolic extracts of "toronjil azul" (Dracocephalum moldavica L.). Methodology: The forced swimming test (FST) and tail suspension test (TST) were performed on CD-1 mice to evaluate the antidepressant activity of the ethanolic extracts. The ethanolic extracts were administered orally at an 80 and $100 \mathrm{mg} / \mathrm{kg}$. The animals were dosed 1, 6 and $24 \mathrm{~h}$ before initiating the FST assay and 40 minutes before for the TST assay. Imipramine and fluoxetine were dosed at $15 \mathrm{mg} / \mathrm{kg}$, while the flavonoid quercetin was given an a lower concentration of $10 \mathrm{mg} / \mathrm{kg}$ as a positive controls. Results: The extracts of Dracocephalum moldavica L. and significantly decreased the immobility time in the FST and TST assays when compared with the negative control and reported similar values than those obtained with the positive controls. Conclusion: The results obtained indicate that extract of Dracocephalum moldavica L. have antidepressant effect similar to those obtained by.

Key words: Depression, Dracochepalum moldavica L., Forced swim test, Tail suspension test.

\section{INTRODUCTION}

Depression is a mental disorder which according with the World Health Organization is the second cause of disability worldwide, and it has been estimated that around 350 million people suffer from depression. Depression is characterized by a depressed mood and loss of interest or pleasure in almost all daily activities. Depressed individuals have feelings of worthlessness or guilt, difficulty in thinking, concentrating or making decisions. In the most severe cases situations recurrent thoughts of death or suicidal ideation are common; according to the World Health Organization about 800000 people commit suicide worldwide. There are also physical alterations including decreased energy, loss of appetite, changes in body weight, altered sleep patterns and psychomotor activity. At least seven to eight of the after mentioned symptoms have to be presented during a period of two or more weeks to have a positive diagnostic according to the Diagnostic and Statistical Manual of Mental Disorders. ${ }^{1,2}$

The physiopathology of the disease is explained by the monoamine hypothesis which states that a deterioration of the serotonergic and noradrenergic systems causes a decrease in the production of monoamines altering the chemical brain communication. ${ }^{3}$ Recently, it has been shown that an increase of stress affecting cortisol release is associated with brain cell damage and reduction of the hippocampal specifically the CA1-CA3 region. ${ }^{4}$ During centuries many plants and more recently hallucinogens mushrooms with the psicoactive compound spilocybin, have been associated with an efficient and safe antidepressive effect. Among the several plants studies with an antidrepessive action, Dracocephalum moldavica $L$. is a plant that belongs to the family Lamiaceae. The plant is a herbaceous type with a height of $80 \mathrm{~cm}$, native to Central Asia, but they can be reproduced throughout the eastern and central part of Europe. According with to popular knowledge, the plant has been used vastly to combat heart disease, blood pressure, angina, atherosclerosis, neuralgia, migraine, headache and toothache. Additionally, it has been reported that some extracts of the plant have sedative and analgesic effects. $^{5,6}$

In Mexico Dracocephalum moldavica L. has been adapted in the central region of the country, growing during all year, even though the weather conditions are different from the ones in its found homeland. DmL has a characteristic smell of lemon giving the presence of the essential oils, geraniol and citral, which have been describied with a relax and tranquilizing effect. In traditional Mexican medicine, Dracocephalum moldavica $L$. is known as "toronjil azul or toronjil chino" and it has been used as a tranquilizing and sedative remedy. Moreover, a synergic effect, on the sedative and tranquilizing effect of toronjil azul is seen when administered together with Agastache mexicana ssp. xolocotziana also known as "toronjil blanco".,78

In Mexico its main use is the combination of two plants known "toronjil morado", it has been reported that this infusion is known as "the three toronjiles" which is recommended for some nervous diseases., Some studies of Agastache species have been used in traditional medicine, recent studies reveal the frequent appearance of flavonoid glycosides and flavonoids compounds. Since it is well known that
Cite this article: Jiménez Zúñiga MI, Hurtado Mariles AJ, Castrejón Flores JL, Mondragón Herrera JA, Ramírez Sotelo MG, Cerón Montes Gl, et al. Antidepressant-Like Effects of Dracocephalum moldavica L. in Mouse Models of Immobility Tests. Pharmacog J. 2019;11(5):976-83. 
some flavonoid compounds can act on the Central Nervous System (CNS). ${ }^{9-11}$ The presence of this type of compounds in Agastache species could be related to their therapeutic effects. ${ }^{12}$

However, the use of these two plants has not been studied for their effectiveness in the treatment of different diseases, despite their use in traditional Mexican medicine, there is no data on the activity in the CNS. Baring in mind the above, the main aim of this work was to evaluate the effects on the CNS of extract ethanolic of Dracocephalum moldavica L., using the models of the Forced Swimming Test and Tail Suspension Test. In addition, acute toxicity was evaluated and the identification and quantification of the extract components was carried out.

\section{MATERIALS AND METHODS}

\section{Plants material}

Aerial parts of Dracocephalum moldavica L. (DmL) were collected in "San José Tlacotitlán, Santiago Mamalhuazuca, Ozumba, Estado de Mexico". The botanical identification was carried out by M. en C. Abigail Aguilar Contreras, and a sample of this specie was deposited at the Medicinal Herbarium of the Centro Médico Nacional Siglo XXI, IMSS (Registry No. 16258).

\section{Preparation of ethanolic extract of Dracocephalum moldavica L. (DmL-EtOH)}

Aerial parts of DmL (50 g), were dried in an oven (FELISA FE-291A) at $45^{\circ} \mathrm{C}$ for 3 days and extracted using a sonicator (AS3120B ultrasonic cleaner) 3 successively rounds with $96 \%$ ethanol $(\mathrm{EtOH})$ at room temperature. Next the extracts were concentrated under reduced pressure at $45^{\circ} \mathrm{C}$. Pharmacological evaluation was using $80 \%$ Tween as the vehicle for the administration of the (DmL-EtHO) extracts and the doses were expressed in milligrams of DmL per kilogram of body weight per mouse.

\section{Phytochemical screening and quantification of the secondary metabolites}

The (DmL-EtOH) extracts were qualitatively tested for the presence of phytochemicals as it has been described before. ${ }^{13}$

The quantification of the secondary metabolites, including phenols, tannis and flavonoids concentrations was determinate by colorimetric methods using gallic acid, tannic acid and quercetin as standards. ${ }^{14-16}$

\section{Chemical characterization of (DmL-EtOH)}

$5 \mathrm{~g}$ of the dry plant was weighed, added in $20 \mathrm{~mL}$ of methanol and extracted by solid-liquid extraction for 12 hours. Then, $1 \mathrm{~mL}$ of the extract was adsorbed in silica gel 60 with a particle size of $0.063-0.2$ $\mathrm{mm}$, eluted with $25 \mathrm{~mL}$ of methanol and filtered with a membrane of $0.22 \mu \mathrm{m}$

A mobile phase was prepared with methanol and acid water $(0.1 \%$ phosphoric acid) in a ratio of $77: 23$. All the components of the mobile phase were filtered on a $0.22 \mu \mathrm{m}$ membrane. The temperature of the column (Corctecs ${ }^{\oplus} \mathrm{C}-18$ a particle size of $2.7 \mu \mathrm{m}$ ) was maintained at $25^{\circ}$ $\mathrm{C}$, the volume of the injection loop was $10 \mu \mathrm{L}$ and the flow of the mobile phase was $0.5 \mathrm{~mL} / \mathrm{min}$. Subsequently, the column was equilibrated for 30 min with the mobile phase. The standards and the extracts were read at different wavelengths in an UHPLC model Acquity Arc of the Waters brand. ${ }^{17}$

\section{Animals}

Adult male CD-1 mice (25-35 g) were housed five per cage in a temperature-controlled $\left(22-23^{\circ} \mathrm{C}\right)$ room under inverted light/dark conditions (12 h light/dark cycle, lights turned on at 22:00 h) and were maintained on standard rodent feed and allowed to drink water. All animals were handled in agreement with the general principles of laboratory animal care (NIH publication \# 85-23, revised in 1985; directive 2010/63/EU of the European parliament and of the council) and the 'Norma Oficial Mexicana.. ${ }^{18}$ Declaration of Helsinki on the welfare of experimental animals. All behavioral evaluations were performed between 9:00 and 16:00 $\mathrm{h}$ and the complete experimental sessions were videotaped and analyzed by a blind observer who was unaware of the treatment conditions.

\section{Drugs}

All the drugs in this study were administered orally in a total volume of $10.0 \mathrm{~mL} / \mathrm{Kg}$ of body weight. The DmL-EtOH extract were dissolved in $80 \%$ Tween. Imipramine (Psicofarma Mexico City, Mexico), fluoxetine (Psicofarma Mexico City, Mexico) and quercetin (Aldrich-Sigma, Mexico City, Mexico) were dissolved in an isotonic solution $(0.9 \%$ $\mathrm{NaCl}$ ). The control animals received the same vehicle volume (isotonic solution, $0.9 \% \mathrm{NaCl}$ ).

\section{Antidepressant-like effect in the forced swimming test} (FST)

Mice were individually placed in glass cylinders (height: $40 \mathrm{~cm}$, diameter: $19.5 \mathrm{~cm}$ ) containing $35 \mathrm{~cm}$ of water at $25 \pm 1^{\circ} \mathrm{C}$. All animals were forced to swim for a 15 min period (pre-test), followed by a 5 -min session (test) at $24 \mathrm{~h}$ later. ${ }^{19-23}$

Six independent groups of mice ( $n=5$ per group) were used in this experiment. Two groups were administered orally with (DmL-EtOH) 80 and $100 \mathrm{mg} / \mathrm{Kg}$. Additionally, one group was administered quercetin (QUE) while two independent groups were used as positive controls receiving imipramine (IMI) and fluoxetine (FLU) $15 \mathrm{mg} / \mathrm{Kg}$. All test sessions were videotaped, and afterward, the immobility time accumulated during the test was registered by an observer that was unaware of the pharmacological treatments.

\section{Tail suspension test (TST)}

The total duration of immobility of the different groups induced by tail suspension was measured according to the method Steru et al. and Can et al. ${ }^{24,25}$ The mice were suspended from the edge of a table at $50 \mathrm{~cm}$ above the floor with adhesive tape placed approximately $1 \mathrm{~cm}$ from the tip of the tail. Immobility time was recorded during a $6 \mathrm{~min}$ period.

\section{Acute toxicity study $\left(\mathrm{LD}_{50}\right)$}

The $\mathrm{LD}_{50}$ of the extracts was determined by administration through orally by modifying Lorke's method. ${ }^{26}$ Briefly, in the first stage, the ethanolic extracts was administered orally at increasing doses of 250 , 500,750 and $1000 \mathrm{mg} / \mathrm{Kg}$ to the four groups of three mice each. The animals were observed for $1 \mathrm{~h}$ for signs and symptoms of toxicity. Later observations were made every $24 \mathrm{~h}$ for week. In the second phase, higher doses of 2500 , and $5000 \mathrm{mg} / \mathrm{Kg}$ were administered to the groups consisting of three animals. These mice were carefully observed until their total recovery or death. The surviving animals were observed for 14 days to determinate mortality.

\section{Statistics}

The results are expressed as mean \pm S.E.M. Statistical analysis of the data was performed using one-way analysis of variance ANOVA followed by Dunnet's multiple comparison tests. A level of significance $(\mathrm{P}<0.05)$ was considered for each test, using the software GraphPad Prism 5.

\section{RESULTS}

Phytochemical studies and quantification of the secondary metabolites. The phytochemical screening examination and the quantification on the interest compounds of the ethanolic extract are shown in (Table 1).

The content of total phenols was determined by the Folin-Ciocalteu method of the ethanolic extract amounted to $0.933 \pm 0.105$ (DmL- 
EtOH) mg equivalents of gallic acid (GAE)/g plant. The total flavonoids in the total extract were $0.110 \pm 1 \times 10^{-5}(\mathrm{DmL}-\mathrm{EtOH}) \mathrm{mg}$ equivalents to quercetin $(\mathrm{QE}) / \mathrm{g}$ of plant. Quantification of tannins was determined by the Folin-Ciocalteu method. The ethanolic extract is the one that contains the highest amount of total tannins $0.204 \pm 4$ $\times 10^{-4}(\mathrm{DmL}-\mathrm{EtOH}) \mathrm{mg}$ tannic acid equivalents (TAE)/g plant.

\section{Effect of extracts in the FST}

The results of (DmL-EtOH) are shown in Figure 1. The results showed that the drugs, IMI $(15 \mathrm{mg} / \mathrm{Kg})$ and FLU $(15 \mathrm{mg} / \mathrm{kg})$ and the natural compound QUE $(10 \mathrm{mg} / \mathrm{Kg})$ significantly reduced the immobility time, the mice showed more activity, compared to the control group only administered with the vehicle. Importantly a similar effect to that seen with the drugs is seen with the (DmL-EtOH) total extract at $100 \mathrm{mg} / \mathrm{Kg}$ and $80 \mathrm{mg} / \mathrm{Kg}$. Additionally, we determined the swimming time in all the groups under the differnte treatments (Figure 2).

\section{Effect of extracts in the TST}

To confirm the FST results, we determined the anti-depressant effect using the tail suspension test (TST). Figure 3 shows the result of the test under the different treatments. These results corroborate that the (DmL-EtOH) total extract at a dose of $100 \mathrm{mg} / \mathrm{Kg}$ and $80 \mathrm{mg} /$ $\mathrm{Kg}$ significantly reduced the immobility time compared to the control group (vehicle).

\section{Acute toxicity tests}

Toxicity performed on the ethanolic extracts of (DmL-EtOH) did not show any toxicity in terms of $\mathrm{LD}_{50}$ indices according to the Lorke classification; however, some mild adverse effects including sleep and decrease of locomotor activity were seen when the ethanolic extract (DmL-EtOH) was administered at a dose of $750 \mathrm{mg} / \mathrm{Kg}$.

\section{Phytochemical study of extracts of (DmL-EtOH)}

The determination of chemical compounds of the extract (DmL$\mathrm{EtOH}$ ), was achieved by the conditions established in the experimental section. The results showed the presence of quercetin and catequin, according to the retention time of 1 minutes, the presence of these compounds could be observed in comparison with the reference standards (Figure 4).

\section{DISCUSSION}

According to the literature consulted Dracocephalum moldavica L., have been used as an ingredient in the preparation of some foods, tea and as remedy in traditional medicine for the treatment of different stomach disorders, headaches, in the treatment of nerves and congestion. Moreover, some studies have reported an antioxidant effect of these plants as well as their cardioprotective and vasodilatory effect. ${ }^{5,6,27,28}$ However, there are not pharmacological studies on the antidepressant, sedative and anxiolytic effects of these plants until now. Therefore, the aim of the present study was to evaluate the antidepressant effect produced by the aerial parts of Dracocephalum moldavica $L$. using a despair model.

In the first part of our results we performed a phytochemical screening of ethanolic DmL extract that showed the presence of flavonoids, primarily auronas, chalconas, xanthones, flavones, catechol type tannins and catechol type phenols. Some studies of Agastache species have been demonstrated the presence of flavonoids and flavonoid glucoside compounds. Other reports have shown the presence of oils in DmL plant but this is not the case in our analysis. This difference is attributed to the solvents use in the extraction. In our case we focus on the use of polar solvents, because they favour the accumulation on flavonoids which as it has been well establish have a therapeutic effect on the Central Nervous System (CNS). ${ }^{9-12}$ Thus, the abundance of the

Table 1: Preliminary phytochemical screening of ethanolic extract.

\begin{tabular}{cc}
\hline Class of compound & Ethanolic DmL \\
\hline Alkaloids & + \\
Flavonois & + \\
Phenolic compounds & + \\
Tanins & + \\
Coumarins & - \\
Sesquiterpenlactones & + \\
Reducing sugars & + \\
Cardiac glycosides & + \\
Saponins & + \\
Steroids & + \\
Cyanogenic glycosides &
\end{tabular}

+: Present; -: Absent.

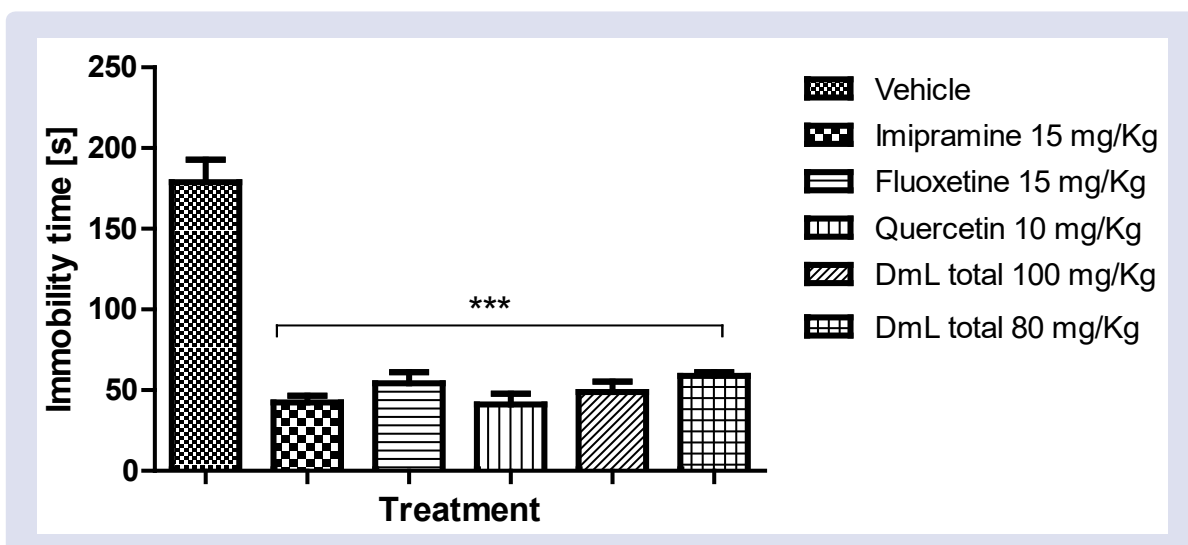

Figure 1: Effect of oral administration of the extracts, immobility time in the forced swimming test. 


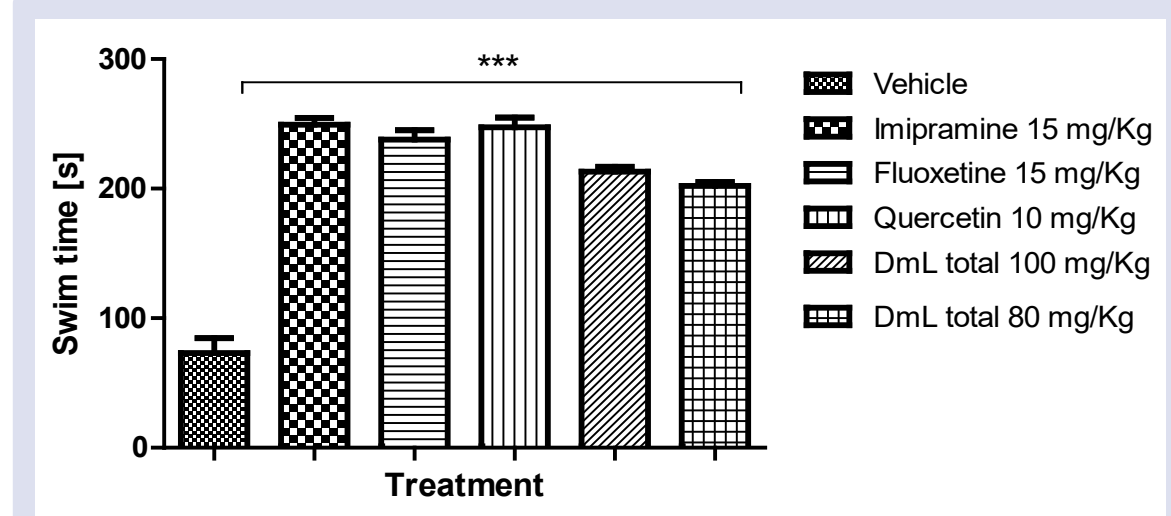

Figure 2: Effect of oral administration of the extracts, swim time in the forced.

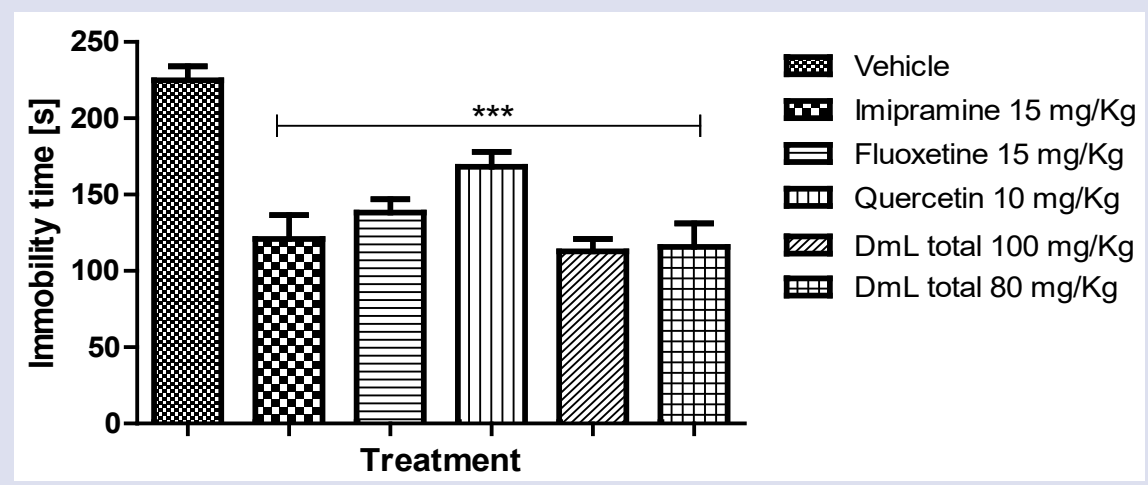

Figure 3: Effect of oral administration of the extracts, immobility time in the tail suspension test.

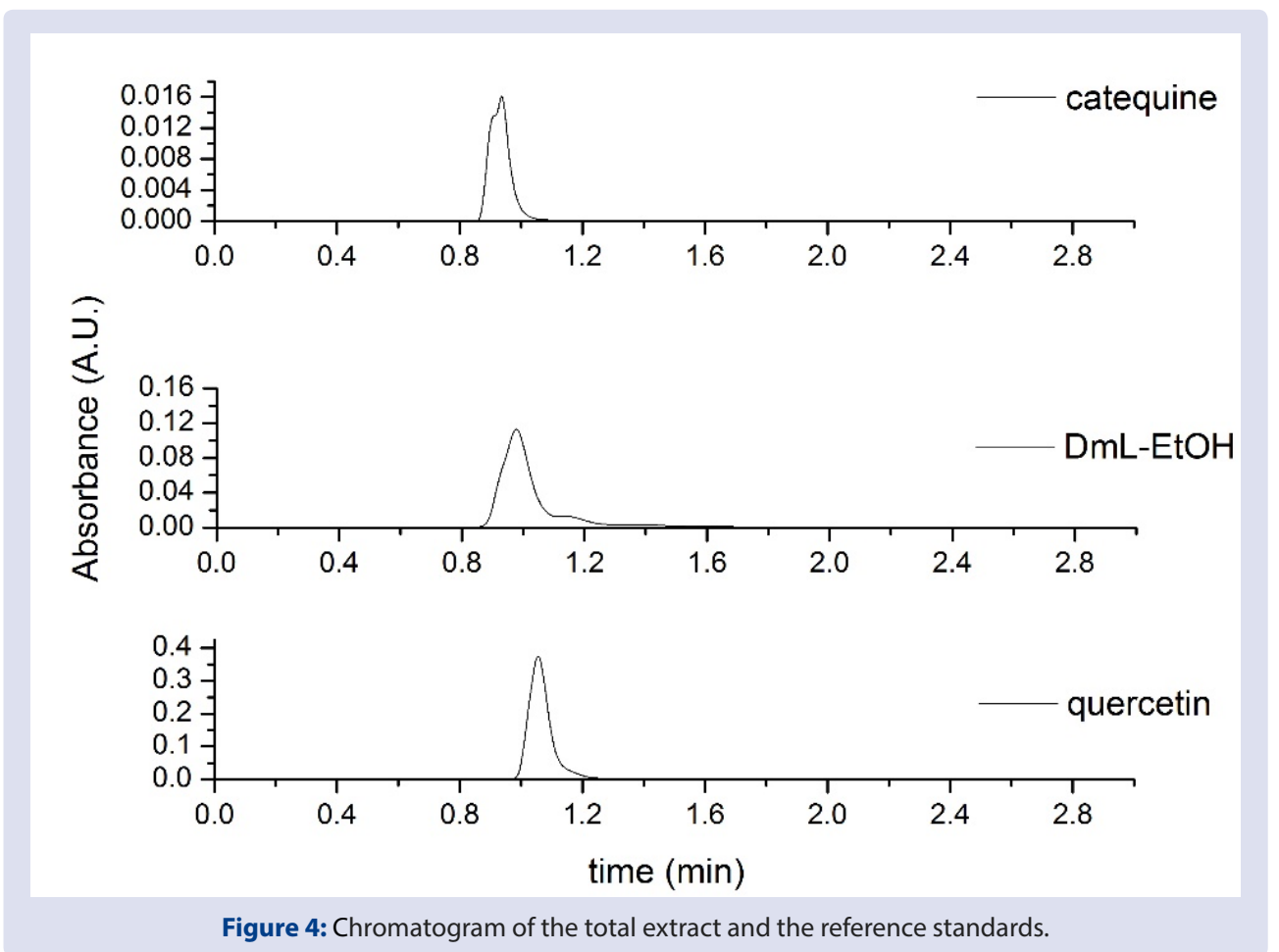


flavonoids compounds in our extract might have the therapeutical effect proposed. ${ }^{12}$

According to Estrada-Reyes et al. ${ }^{29}$ the biological action of flavonoids has been attributed to their antioxidant properties; mainly due to the chelating potential that gives them their chemical structure, in such a way that the antioxidant activity can be due to their reducing capacities per se or to influence the oxidation-reduction (redox) intracellular state. ${ }^{30}$ Additionally, they exert neuroprotective effects in cells and animal models through different biological processes such as the attenuation of oxidative stress. ${ }^{31}$ As it has been well established the antioxidant activity of flavonols and flavones is associated with their structural characteristics composed by the presence of hydroxyl groups in the 3 ' and $4^{\prime}$; positions of the ring $\mathrm{B}$, the hydroxyl group in C-3 and an unsaturation of ring $C$ giving an effective capacity to capture free radicals, a requirement for a maximum antioxidant capacity. ${ }^{31}$ Phytotherapy studies have confirmed that flavonoids are able to influence the mood and activity of the CNS.

To evaluate the antidepresent effect of our extracts we used the forced swim and tail suspension tests which are vastly used for the determination of antidepresive effect of chemical synthetized compounds and plants extracts. During the experimental development, in the test prior to the study, acute stress is induced in the mice, which is easy to observe with a behavior of immobility, this behavior is improved by some antidepressants such as IMI and FLU in the period of the test. ${ }^{20}$, ${ }^{32,33}$ The results show that the repeated orally administration of $D m L$ at a dose of $100 \mathrm{mg} / \mathrm{kg}$ of the total extract induced a statistically significant reduction in the immobility time similar to the effect obtained by commercially used drugs, imipramine and fluoxetine, and quercetine an isolated flavonoid with antidepresent effect. ${ }^{34}$ It has been shown that swimming has an effect in the levels of serotonin. Previous studies have shown that the administration of fluoxetine at concentrations of 5,10 and $20 \mathrm{mg} / \mathrm{kg}$ and, a single dose of $10 \mathrm{mg} / \mathrm{kg}$ of quercetin both selective inhibitor of serotonin reuptake and a non selective inhibitor of noradrenaline and serotonin used as a positive control in our experiments respectively, increases the mobility of previously stressed mice. Thus, it is possible that our extract has a pharmacological effect over the levels of both neurotransmitters. However, more studies are needed to determine the exact antidepresive mechanism and the compound(s) associated with the effect. ${ }^{35-40}$

Another aim of the present study was to evaluate the toxicity of the ethanolic extracts administrated orally from the aerial parts of $D m L$. As mentioned in the results section, the compound showed a low level of toxicity according to the classification proposed by Abou-Donia, giving that rising doses up to $5000 \mathrm{mg} / \mathrm{kg}$ were not associated with death, although moderate adverse effect were seen. Thus our extract not only was efficient for the treatment of depression but also resulted safer when compared with other authors. ${ }^{27,41}$

According to Martinez et al..$^{42}$ the extracts of Dracochepalum moldavica $L$. demonstrated the presence of apigenin 7-O- $\beta$-D- $\left(6^{\prime \prime}\right.$-O-malonyl)glucoside, according to Estrada et al. ${ }^{12}$ in studies conducted with Agastache, the presence of compounds such as flavonoids (C-glycosides of apigenin and luteolin) was found, compounds to which the anxiolytic property is attributed.

According to Zielinka et $a l .{ }^{43}$ the presence of various flavonoids such as apigenin and catechin were detected in Agastache. According to the reports, the content of various flavonoids such as apigenin and quercetin was observed, this was detected when the period of flowering began in the spices of Agastache.

\section{CONCLUSIONS}

The results obtained indicate that extract of $D m L$, have antidepressant effect similar to those obtained by commercially available drugs. Moreover, the extract resulted less toxic and with minor adverse effect when compared with other methods of extraction. Nonetheless, more studies are needed to determine and isolate the active compound and elucidate the mechanism of action.

\section{ACKNOWLEDGEMENTS}

The authors thank the Medicinal Herbarium of Centro Médico Nacional Siglo XXI for the characterization of the study plants.

\section{CONFLICTS OF INTEREST}

All authors declare that there are no conflicts of interest.

\section{REFERENCES}

1. American psychiatric association. Section II: Diagnostic criteria and codes, depressive disorders. Diagnostic and statistical manual of mental disorders (DSM-5 ${ }^{\circledR}$ ). American Psychiatric Pub. 2013;155-88.

2. World health organization (WHO). Depression. Fact sheet $N^{\circ} 369$ (No. Fact sheet N³69). 2012.

3. Taniguti EH, Ferreira YS, Stupp IJV, Fraga-Junior EB, Mendonça CB, Rossi FL, et al. Neuroprotective effect of melatonin against lipopolysaccharide-induced depressive-like behavior in mice. Physiol Behav. 2018;188:270-5.

4. Willard SL, Riddle DR, Forbes ME, Shively CA. Cell number and neuropi alterations in subregions of the anterior hippocampus in a female monkey model of depression. Biol Psychiat. 2013;74(12):890-7.

5. Dastmalchi K, Dorman HD, Koşar M, Hiltunen R. Chemical composition and in vitro antioxidant evaluation of a water-soluble Moldavian balm (Dracocephalum moldavica L.) extract. LWT-Food Sci Technol. 2007;40(2):239-48.

6. Sultan A, Aisa HA, Eshbakova KA. Flavonoids from Dracocephalum moldavica Chem Nat Compd. 2008;44(3):366-7.

7. Holm Y, Galambosi B, Hiltunen R. Variation of the main terpenes in dragonhead (Dracocephalummoldavica L.) during growth. Pr Phyt Soc. 1988;3(3):113-5.

8. Linares E, Bye R, Flores B. Plantas medicinales de México, usos y remedios tradicionales. Jardín Botánico del Instituto de Biología. 1999.

9. Estrada-Reyes R, Ubaldo-Suárez D, Araujo-Escalona AG. Los flavonoides y el Sistema Nervioso Central. Salud Ment. 2012;35(5):375-84.

10. Fernández S, Wasowski C, Paladini AC, Marder M. Sedative and sleep enhancing properties of linarin, a flavonoid-isolated from Valeriana officinalis. Pharmacol Biochem Be. 2004;77(2):399-404.

11. Marder M, Viola $H$, Wasowski C, Fernández S, Medina JH, Paladini AC 6-Methylapigenin and hesperidin: new valeriana flavonoids with activity on the CNS. Pharmacology Biochem Be. 2003;75(3):537-45.

12. Estrada-Reyes R, Hernández EA, García-Argáez A, Hernández MS, Linares E, Bye R, et al. (2004) Comparative chemical composition of Agastache mexicana subsp. mexicana and A. mexicana subsp. xolocotziana. Biochem Syst Ecol. 2004;32(7):685-94

13. Valencia G, Garín M. Manual de prácticas de productos naturales, (1a Ed.) México DF, 2010;31-5.

14. Chang CC, Yang MH, Wen HM, Chern JC. Estimation of total flavonoid content in propolis by two complementary colorimetric methods. J Food Drug Anal. 2002;10(3):178-82.

15. Makkar HP, Blümmel M, Borowy NK, Becker K. Gravimetric determination of tannins and their correlations with chemical and protein precipitation methods. J Sci Food Agr. 1993;61(2):161-5.

16. Singleton VL, Rossi JA. Colorimetry of total phenolics with phosphomolybdicphosphotungstic acid reagents. Am J Enol Viticult. 1965;16(3):144-8.

17. Sri KV, Ratna JV, Annapurna A, Kumar R. Reversed-phase HPLC Method for determination of quercetin in human plasma. Asian J Chem. 2009;21(1):101.

18. NOM-062-ZOO-1999. Norma oficial Mexicana. Secretaría de Salud Especificaciones técnicas para la producción, cuidado y uso de los animales de laboratorio 1999 (Accessed December 2016).

19. Murakami T, Yamane $H$, Tomonaga S, Furuse M. Forced swimming and imipramine modify plasma and brain amino acid concentrations in mice. Eur $\mathrm{J}$ Pharmacol. 2009;602(1):73-77.

20. Porsolt RD, Le Pichon M, Jalfre ML. Depression: A new animal model sensitive to antidepressant treatments. Nature. 1977;266(5604):730-732.

21. Porsolt RD, Bertin A, Jalfre M. Behavioral despair in mice: a primary screening test for antidepressants. Arch Int Pharmacod T. 1977;229(2):327-36.

22. Schürmann da Silva AF, De Andrade JP, Bevilaqua LRM, De Souza MM, Izquierdo I, Heriques AT, et al. Anxiolytic-, antidepressant- and anticonvulsant-like effects of the alkaloid montanine isolated from Hippeastrum vittatum. Pharmacology Biochem Be. 2006;85(1):148-54.

23. XuY, Ku BS, Yao HY, Lin YH, Ma X, Zhang YH, et al. The effects of curcumin on depressive-like behaviors in mice. Eur J Pharmacol. 2005;518(1):40-6. 
24. Can A, Dao DT, Terrillion CE, Piantadosi SC, Bhat S, GouldTD. The tail suspension test. JoVE JVis Exp. 2012;59:1-5.

25. Steru L, Chermat $R$, Thierry B, Simon P. The tail suspension test: a new method for screening antidepressants in mice. Psychopharmacology. 1985;85(3):36770.

26. Lorke D. A new approach to practical acute toxicity testing. Archives of Toxicology. 1983;54:275-87.

27. Martínez-Vázquez M, Estrada-Reyes R, Martínez-Laurrabaquio A, LópezRubalcava C, Heinze G. Neuropharmacological study of Dracocephalum moldavica L. (Lamiaceae) in mice: Sedative effect and chemical analysis of an aqueous extract. J Ethnopharmacology. 2012;141(3):908-17.

28. Najafi M, Ghasemian E, Fathi AF, Garjani A. Effects of total extract of Dracocephalum moldavica on ischemia/reperfusion induced arrhythmias and infarct size in the isolated rat heart. Iran J Basic Med Sci. 2009;11(4):229-35.

29. Estrada-Reyes R, Lopez-Rubalcava C, Ferreyra-Cruz OA, Dorantes-Barrón AM, Heinze G, Aguilar JM, et al. Central nervous system effects and chemical composition of two subspecies of Agastache mexicana; an ethnomedicine of Mexico. J Ethnopharmacology. 2014;153(1):98-110.

30. Brand-Williams W, Cuvelier ME, Berset CLWT. Use of a free radical method to evaluate antioxidant activity. LWT-Food Sci Technol. 1995;28(1):25-30.

31. Barron-Yanez RM, Del Rosario M, Soto MR, Colinas T, Kite G. Flavonoids and antioxidant activity of Calia secundilfora (Ort.) Yakovlev. Rev Fitotec Mex. 2011;34(3):151-7.

32. Borsini F, Meli A. Is the forced swimming test a suitable model for revealing antidepressant activity? Psychopharmacology. 1988;94(2):147-60.

33. Redrobe JP, Bourin M, Colombel MC, Baker GB. Psycopharmacological profile of the selective serotonin reuptake inhibitor, paroxetine: implication of noradrenergic and serotonergic mechanisms. J Psychopharmacol. 1998;12(4):342-55.
34. Romano B, Pagano E, Montanaro V, Fortunato AL, Milic N, Borrelli F. Novel insights into the pharmacology of flavonoids. Phytother Res. 2013;27(11):158896.

35. Bhutada P, Mundhada Y, Bansod K, Ubgade A, Quazi M, Umathe S, et al Reversal by quercetin of corticotrophin releasing factor induced anxiety-and depression-like effect in mice. Prog Neuro-Psychoph. 2010;34(6):955-60.

36. Cryan JF, Lucki I. Antidepressant-like behavioral effects mediated by 5-hydroxytryptamine2C receptors. J Pharmacol Exp Ther. 2000;295(3):1120-6.

37. Detke MJ, Rickels M, Lucki I. Active behaviors in the rat forced swimming test differentially produced by serotonergic and noradrenergic antidepressants. Psychopharmacology. 1995;121(1):66-72.

38. Haleagrahara N, Radhakrishnan A, Lee N, Kumar P. Flavonoid quercetin protects against swimming stress-induced changes in oxidative biomarkers in the hypothalamus of rats. Eur J Pharmacol. 2009;621(1-3):46-52.

39. Kawabata K, Kawai Y, Terao J. Suppressive effect of quercetin on acute stressinduced hypothalamic-pituitary-adrenal axis response in Wistar rats. J Nutr Biochem. 2010;21(5):374-80.

40. Kumar A, Goyal R. Quercetin protects against acute immobilization stressinduced behaviors and biochemical alterations in mice. J Med Food. 2008;11(3):469-73

41. Abou-Donia MB. General principles. Mammalian toxicology. Wiley academic New Delhi, India. 2015;1-14

42. Estrada-Reyes R, Lopez-Rubalcava C, Ferreyra-Cruz OA, Dorantes-Barrón AM Heinze G, Aguilar JM, et al. Central nervous system effects and chemical composition of two subspecies of Agastache mexicana; an ethnomedicine of Mexico. J Ethnopharmacology. 2014;153(1):98-110.

43. Zielińska S, Matkowski A. Phytochemistry and bioactivity of aromatic and medicinal plants from the genus Agastache (Lamiaceae). Phytochemistry Reviews. 2014;13(2):391-416.

\section{GRAPHICAL ABSTRACT}
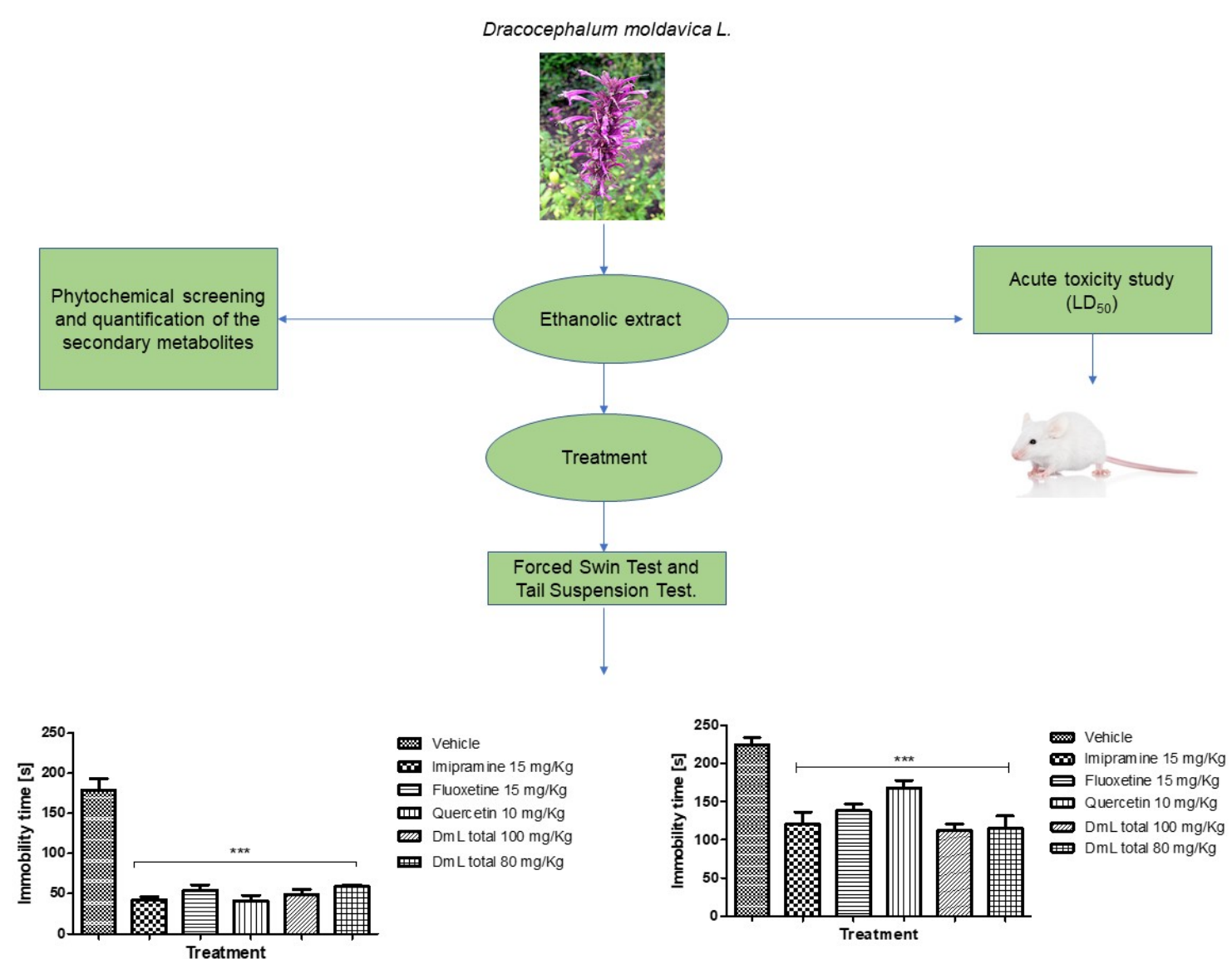


\section{ABOUT AUTHORS}

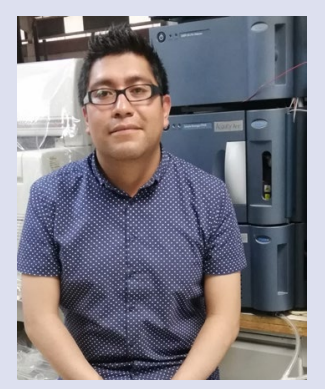

Marcos Ignacio Jiménez-Zuñiga he obtained his PhD degree in 2019 at the Instituto Politecnico Nacional-UPIBI of Mexico City. He is currently a professor and researcher at the Technological University of Tecámac. His research projects focus on pharmacognosy-based medicine to try to resolve the mechanism of action of secondary metabolites, especially in diseases of the Central Nervous System such as depression.

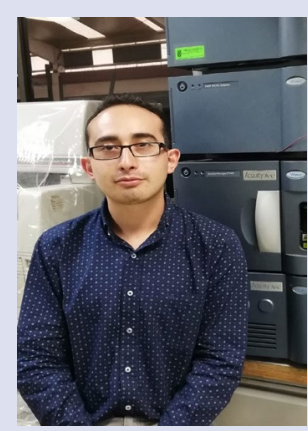

Alejandro Jonathan Hurtado-Mariles he obtained his PhD degree in 2019 at the Instituto Politecnico Nacional-UPIBI of Mexico City. He is currently a professor and researcher at the Technological University of Tecámac and in the Instituto Politecnico Nacional. His research projects focus on pharmacognosy-based medicine to try to resolve the mechanism of action of secondary metabolites, especially in diseases of the Central Nervous System such as epilepsy.

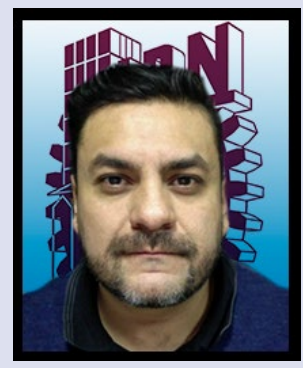

Jose Luis Castrejon-Flores holds a PhD in Pharmacology from the MRC Centre for Drug Safety Science at The University of Liverpool (UK). He has published papers describing the chemical and cellular mechanisms of T-cell activation in the presence of sulfonamides metabolites. Currently, his research focuses on evaluating the efficacy and safety of molecules obtained from different sources including metabolites extracted from plants. Since 2011, he is principal investigator at Instituto Politecnico Nacional in Mexico City, and group leader of the Laboratory of efficacy and safety of molecules with pharmacology activity.

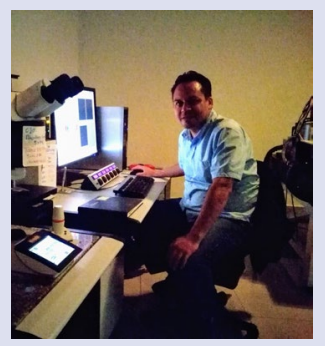

José Antonio Mondragón-Herrera obtained his Ph. D degree in Biological and Health Sciences in 2014 from Autonomous Metropolitan University, Mexico. Currently, he is a professor at National Polytechnic Institute since 2016 and a researcher in the Molecular Pathology Laboratory of the Cardiology Hospital in the Medical Center, XXI Century. His research projects are focus on Neurotransmitters and Neurosteroids on different animal models, to try to determine neuronal modifications on several diseases using histological and biomolecular techniques.

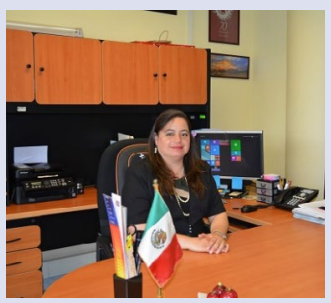

María Guadalupe Ramírez-Sotelo received her PhD degree in Genetics and Molecular Biology from Advanced Research Centre (CINVESTAV) of National Polytechnic Institute (IPN) in 2006. She is a professor-researcher at the Professional Interdisciplinary Unit of Biotechnology (UPIBI) of IPN. She also obtained a Professional Diploma in "High Direction" in 2018 by National Association of Engineering Faculties and Schools. She is Biotechnology Network (RedBio) Coordinator of the National Polytechnic Institute (IPN). She has a special interest in peptides extracted from plants with antimicrobial and antioxidant activity. 


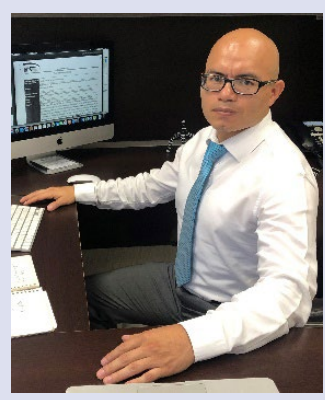

Genaro Cerón-Montes received his Ph.D degree from Research Center for Applied Science and Advanced Technology of the National Polytechnic Institute (CICATA-IPN), México in (2015). He is a professor-researcher at the Technological University of Tecámac (UTTEC). He has 10 years of academic teaching experience in applied bioengineering in the Engineering Biotechnology Program. His researches focus on natural products bioseparations and delivery systems comprising nanotechnology, microfiltration, ultrafiltration and preparative chromatography for chemical, pharmaceutical, and food applications. He has leaded projects in cooperation with the medical industry to develop human medical utensils relate to the skin and bones.

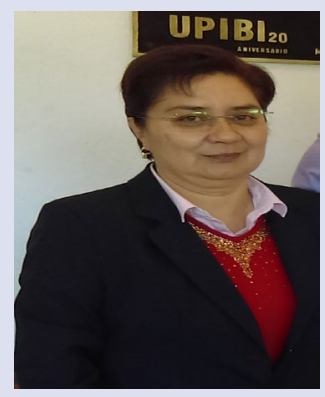

Yolanda de las Mercedes Gómez y Gómez has a PhD on Biological Sciences on 2011 by Universidad Nacional Autónoma of México, Ciudad of México. She currently work in the Instituto Politécnico Nacional-UPIBI since 1990, as a full time teacher. She has worked for many year with secondary metabolites of medicinal plants with pharmacological activity \& also with the development drug release system at the microarray and nanomatrix scale.

Cite this article: Jiménez Zúñiga MI, Hurtado Mariles AJ, Castrejón Flores JL, Mondragón Herrera JA, Ramírez Sotelo MG, Cerón Montes GI, et al. Antidepressant-Like Effects of Dracocephalum moldavica L. in Mouse Models of Immobility Tests. Pharmacog J. 2019;11(5):976-83. 